\title{
Serum Vascular Endothelial Growth Factor Levels Lack Predictive Value in Patients with Active Ankylosing Spondylitis Treated with Golimumab
}

\author{
Jürgen Braun, Xenofon Baraliakos, Kay-Geert A. Hermann, Stephen Xu, and Benjamin Hsu
}

\begin{abstract}
Objective. To assess vascular endothelial growth factor (VEGF) correlations with new bone formation and bone marrow edema in patients with ankylosing spondylitis (AS) treated with golimumab (GOL). Methods. Following placebo control (through weeks 16 and 24), GO-RAISE (A Multicenter Randomized, Double-blind, Placebo-controlled Trial of Golimumab, a Fully Human Anti-TNF- $\alpha$ Monoclonal Antibody, Administered Subcutaneously, in Subjects with Active Ankylosing Spondylitis; ClinicalTrials.gov: NCT00265083) all patients received GOL; sera/images were available at weeks 0, 104, and 208. Lateral spinal radiographs and magnetic resonance imaging (MRI) were scored using the modified Stokes Ankylosing Spondylitis Spine Score (mSASSS) and the Ankylosing Spondylitis Spinal MRI activity score, respectively.

Results. VEGF levels and the mSASSS did not significantly correlate. Logistic regression analyses showed no association between VEGF levels and an increased risk of syndesmophyte formation at weeks 104 and 208. Pretreatment/Week 14 VEGF did not predict MRI scores/changes at Week 104. Conclusion. Serum VEGF did not predict radiographic progression/spinal inflammation in patients receiving antitumor necrosis factor. (First Release March 1 2016; J Rheumatol 2016;43:901-6; doi:10.3899/jrheum.150897)
\end{abstract}

Key Indexing Terms: ANKYLOSING SPONDYLITIS BIOLOGIC

BIOMARKERS

TUMOR NECROSIS FACTOR RADIOGRAPH

Ankylosing spondylitis (AS) is a chronic rheumatic disease of the axial skeleton, initially characterized by spinal inflammation and typically followed by new bone formation evident as syndesmophytes and ankylosis. Biologic agents inhibiting cytokines in the AS inflammatory cascade, including tumor necrosis factor (TNF), can significantly reduce AS signs/symptoms ${ }^{1}$ and also have significantly reduced magnetic resonance imaging (MRI)-detected spinal inflammation ${ }^{2,3}$. In the phase III, randomized, placebo-controlled, GO-RAISE trial (A Multicenter Randomized,

From Rheumatology, Rheumazentrum Ruhrgebiet, Herne; Ruhr-University Bochum, Bochum; Radiology, Charité Universitätsmedizin, Berlin, Germany; Biostatistics, and Immunology, Janssen Research \& Development LLC, Spring House, Pennsylvania, USA.

Supported by Janssen Research \& Development LLC and Merck/ Schering-Plough Research Institute Inc. J. Braun has received honoraria for talks, advisory boards, paid consultancies, and grants for studies from Janssen. S. Xu and B. Hsu are employees of Janssen.

J. Braun, MD, Department of Rheumatology, Rheumazentrum Ruhrgebiet, and Ruhr-University Bochum; X. Baraliakos, MD, Department of Rheumatology, Rheumazentrum Ruhrgebiet, and Ruhr-University Bochum; K.G. Hermann, $M D, P h D$, Radiology, Charité Universitätsmedizin; $S . X u$, MS, Biostatistics, Janssen Research \& Development LLC; B. Hsu, MD, PhD, Immunology, Janssen Research \& Development LLC.

Address correspondence to Prof. J. Braun, Rheumazentrum

Ruhrgebiet, Claudiusstr. 45, 44649 Herne, Germany.

E-mail:j.braun@rheumazentrum-ruhrgebiet.de

Full Release Article. For details see Reprints/Permissions at jrheum.org

Accepted for publication January 9, 2016.
Double-blind, Placebo-controlled Trial of Golimumab, a Fully Human Anti-TNF- $\alpha$ Monoclonal Antibody, Administered Subcutaneously, in Subjects with Active Ankylosing Spondylitis) of golimumab (GOL) in AS, improvements in spinal inflammation were sustained through treatment Week 104 and correlated with improved disease activity and acute-phase reactants ${ }^{2}$. The ability of anti-TNF intervention to reduce spinal radiographic progression is less clear, $4,6,6,7,8$. A biomarker measured prior to/early in anti-TNF therapy that can reliably predict longterm response or reduced radiographic progression would be valuable.

Vascular endothelial growth factor (VEGF) is a signal protein produced by vasculogenesis/angiogenesis-stimulating cells. In rheumatoid arthritis, VEGF is released in response to $\mathrm{TNF}^{9}$. VEGF and transforming growth factor $\beta$ may be involved in psoriasis ${ }^{10}$.

Serum VEGF levels are known to decrease in anti-TNF-treated patients with AS demonstrating clinical improvement ${ }^{11,12}$, and an observational study in spondyloarthritis suggested that VEGF level predicted radiographic progression ${ }^{13}$. We reported on the relationships between serum VEGF levels, radiographic progression, and MRI-detected spinal inflammation using longitudinal data from GO-RAISE (GOL in active AS).

\section{MATERIALS AND METHODS}

Study design/patients. The phase III, multicenter, randomized,

Personal non-commercial use only. The Journal of Rheumatology Copyright $\subset$ $(2016$. All rights reserved. 
placebo-controlled, double-blind, GO-RAISE trial (ClinicalTrials.gov: NCT00265083) was approved by each site's ethical body. All patients provided written informed consent. The GO-RAISE patient selection criteria and study design have been described elsewhere ${ }^{14,15}$. Patients had definite AS according to the modified New York criteria ${ }^{16}$, and active disease defined as a Bath Ankylosing Spondylitis Disease Activity Index ${ }^{17}$ score $\geq 4$ and a total back pain visual analog scale score $\geq 4$.

Patients with active AS were randomly assigned (1:1.8:1.8) to receive subcutaneous doses of placebo, GOL $50 \mathrm{mg}$, or GOL $100 \mathrm{mg}$ at baseline and every 4 weeks (q4week). Randomization was stratified by investigational study site and screening C-reactive protein level $(\leq 1.5 \mathrm{mg} / \mathrm{dl},>1.5 \mathrm{mg} / \mathrm{dl})$. Placebo-randomized patients with $<20 \%$ improvement in total back pain and morning stiffness entered double-blind early escape at Week 16; the study was placebo-controlled from weeks $0-16$. At Week 24 , all patients still receiving placebo crossed over to receive GOL $50 \mathrm{mg}$. All patients continued double-blind treatment through Week 100.

The GO-RAISE longterm extension started with the Week 104 open-label GOL administration. At the investigator's discretion, the GOL dose could be increased from $50 \mathrm{mg}$ to $100 \mathrm{mg}$ q4week or decreased from $100 \mathrm{mg}$ to $50 \mathrm{mg} \mathrm{q} 4$ week during the longterm extension ${ }^{18}$.

Biomarker assessments. Serum samples collected at weeks 0, 4, 14, 24, and 104 of the GO-RAISE trial were tested for selected markers using an ELISA platform by Quintiles Laboratories ${ }^{19}$.

Imaging assessments. Lateral view radiographs of the cervical and lumbar spine were performed at weeks 0,104, and 208. Radiographs were scored using the modified Stoke Ankylosing Spondylitis Spinal Score (mSASSS) method (range $0-72)^{20}$, whereby scores of $0,1,2$, and 3 indicated normal vertebral unit (VU); VU with erosion, sclerosis, or squaring; VU with syndesmophyte; and VU with bridging syndesmophyte, respectively. Serial spine MRI scans of the cervical, thoracic, and lumbar spine in the sagittal plane were acquired at weeks 0,14 , and 104 with the patient in the supine position using 1.5 Tesla scanners and phase array spine or quadrature coils. Image sequences were scored using the Ankylosing Spondylitis spine MRI-activity (ASspiMRI-a) score (range 0-138) 2,21 . Radiographs and MRI scans were read by 2 qualified, experienced, and independent readers who were blinded to treatment information, patient identity, and chronology of the images, as described previously ${ }^{2,8}$.

Syndesmophyte formation was defined as having $\geq 1$ vertebral level on radiograph that changed from a score $<2$ at baseline to 2 or 3 at Week 104 or 208 according to $\geq 1$ reader. Radiographic progression was defined as $\geq 2$-unit change in the mSASSS from baseline to Week 104 or 208.

Statistical analysis. Analyses of imaging data collected through Week 208 used only observed data. ANOVA using van der Waerden ranking methodology assessed differences in VEGF levels at Week 0 and changes at weeks 14 and 24 between patients with mSASSS change $\geq 2$ versus $<2$ at weeks 104 and 208. The relationships between VEGF levels and the ASspiMRI-a scores were assessed by Spearman correlation coefficients $\left(\mathrm{r}_{\mathrm{s}}\right)$. P values were adjusted for testing multiplicity using the Bonferroni methodology.

Logistic regression analyses were conducted to assess whether VEGF levels conferred an increased risk of syndesmophyte formation or radiographic progression at Week 104 or 208 after treatment adjustment. Receiver-operating characteristic (ROC) curve analyses assessed whether VEGF levels were able to predict subsequent syndesmophyte formation or radiographic progression.

\section{RESULTS}

Analysis groups. One hundred forty patients had sera collected for biomarker evaluations, including VEGF; 98 patients at 10 sites with MRI capability participated in the GO-RAISE MRI substudy ${ }^{2}$. Most randomized patients (299/356, 84.0\%) had pre- and posttreatment spine radiographs scored by the mSASSS. Patients with data available for Spearman correlation analysis included 85-109 patients with VEGF and the mSASSS data and 33-69 patients with VEGF and the ASspiMRI-a data, both across the various timepoints assessed. In total, 134 patients had both syndesmophyte and VEGF data at $\geq 1$ timepoint.

About $20 \%-25 \%$ of the patients in each group were initially assigned to placebo. Baseline characteristics for patients with mSASSS and VEGF data through Week 104 were generally consistent with those of the overall GO-RAISE patient population ${ }^{2}$, but showed differences in baseline disease activity between those who progressed and those who did not progress (Appendix 1).

Serum VEGF levels. Spearman correlations indicated no significant association between VEGF and the mSASSS. ROC analysis confirmed there was no association between baseline VEGF and baseline syndesmophytes (data not shown). No significant differences were observed in mean baseline or changes in VEGF levels between patients with change from baseline in mSASSS scores $<2$ (those who did not progress) versus $\geq 2$ (those who progressed) at Week 104 or 208 , or between patients with $\geq 1$ new versus no new syndesmophytes at Week 104 or 208 (Table 1). Logistic regression showed no increased risk of syndesmophyte formation or radiographic progression at Week 104 or 208 to be associated with VEGF levels/changes, and ROC analysis showed that using VEGF at baseline, Week 14, or Week 24 to predict syndesmophyte formation or mSASSS progression at Week 104 or 208 was no different from random chance (data not shown).

While a good correlation score was observed between changes in the ASspiMRI-a levels and VEGF levels at Week $14(\mathrm{p}=0.001)$, other correlational findings indicated that baseline and Week 14 VEGF levels predicted neither future ASspiMRI-a scores nor MRI change scores at Week 104 (Table 2). Figure 1 provides an overview of the VEGF, mSASSS, and ASspiMRI-a findings, demonstrating the initial VEGF decline followed closely by decreased spinal inflammation, with both variables being largely uncoupled from radiographic findings through Week 208.

\section{DISCUSSION}

Previous findings have shown that VEGF levels decrease several weeks after anti-TNF therapy initiation ${ }^{11}$. Our analysis extends these findings by showing that VEGF levels do not predict radiographic progression in patients treated with anti-TNF, although we could confirm that VEGF reduction and MRI-detected spinal inflammation correlate. These findings are consistent with the well-documented ability of TNF antagonists to potently reduce serum inflammatory markers and spinal inflammation acutely, but not to halt radiographic progression in the first years of treatment $^{4,5,6}$, and also with findings from sequential images obtained through MRI and radiograph in the European Ankylosing Spondylitis Infliximab Cohort (EASIC) study ${ }^{22}$.

In the GO-RAISE cohort, Spearman correlation analyses

Personal non-commercial use only. The Journal of Rheumatology Copyright @ (2016. All rights reserved. 
Table 1. Serum VEGF levels (pg/ml) through Week 24 and subsequent radiographic progression or syndesmophyte formation.

\begin{tabular}{|c|c|c|c|}
\hline Timepoint & mSASSS Change $\geq 2$ & mSASSS Change $<2$ & $\mathrm{p}^{*}$ \\
\hline \multicolumn{4}{|l|}{ Week 104} \\
\hline Baseline, $\mathrm{n}$ & 23 & 86 & \\
\hline Median & 103.3 & 77.2 & 0.2169 \\
\hline Mean \pm SD & $113.4 \pm 71.39$ & $91.7 \pm 60.26$ & \\
\hline Change from baseline to Week $14, \mathrm{n}$ & 23 & 78 & \\
\hline Median & -19.3 & -15.0 & 0.5968 \\
\hline Mean \pm SD & $-25.7 \pm 36.26$ & $-20.9 \pm 29.64$ & \\
\hline Change from baseline to Week $24, \mathrm{n}$ & 23 & 77 & \\
\hline Median & -16.1 & -16.5 & 0.6793 \\
\hline Mean \pm SD & $-23.6 \pm 43.65$ & $-18.0 \pm 23.25$ & \\
\hline \multicolumn{4}{|l|}{ Week 208} \\
\hline Baseline, $\mathrm{n}$ & 26 & 67 & \\
\hline Median & 68.3 & 83.9 & 0.3867 \\
\hline Mean \pm SD & $95.3 \pm 65.78$ & $102.9 \pm 65.69$ & \\
\hline Change from baseline to Week $14, \mathrm{n}$ & 25 & 61 & \\
\hline Median & -11.4 & -22.7 & 0.2568 \\
\hline Mean \pm SD & $-17.8 \pm 33.53$ & $-24.2 \pm 32.81$ & \\
\hline Change from baseline to Week $24, \mathrm{n}$ & 25 & 60 & \\
\hline Median & -16.1 & -17.5 & 0.7990 \\
\hline Mean $\pm \mathrm{SD}$ & $-21.6 \pm 34.25$ & $-20.0 \pm 28.71$ & \\
\hline Timepoint & 1 New Syndesmophyte & No New Syndesmophytes & $\mathrm{p}^{* *}$ \\
\hline \multicolumn{4}{|l|}{ Week 104} \\
\hline Baseline, $\mathrm{n}$ & 40 & 94 & \\
\hline Median & 86.6 & 79.9 & 0.2937 \\
\hline Mean \pm SD & $109.7 \pm 73.66$ & $95.7 \pm 66.40$ & \\
\hline Change from baseline to Week $14, \mathrm{n}$ & 38 & 86 & \\
\hline Median & -15.9 & -16.0 & 0.8628 \\
\hline Mean \pm SD & $-20.2 \pm 35.83$ & $-22.0 \pm 35.82$ & \\
\hline Change from baseline to Week $24, \mathrm{n}$ & 38 & 85 & \\
\hline Median & -21.5 & -15.9 & 0.2635 \\
\hline Mean \pm SD & $-25.0 \pm 34.75$ & $-16.7 \pm 26.60$ & \\
\hline \multicolumn{4}{|l|}{ Week 208} \\
\hline Baseline, $\mathrm{n}$ & 49 & 85 & \\
\hline Median & 72.4 & 83.9 & 0.8931 \\
\hline Mean \pm SD & $102.7 \pm 74.94$ & $98.3 \pm 65.19$ & \\
\hline Change from baseline to Week $14, \mathrm{n}$ & 47 & 77 & \\
\hline Median & -13.1 & -17.3 & 0.4734 \\
\hline Mean \pm SD & $-20.0 \pm 37.87$ & $-22.3 \pm 34.51$ & \\
\hline Change from baseline to Week $24, \mathrm{n}$ & 47 & 76 & \\
\hline Median & -16.1 & -16.2 & 0.5956 \\
\hline Mean \pm SD & $-18.2 \pm 35.21$ & $-19.9 \pm 25.51$ & \\
\hline
\end{tabular}

$*$ P value for comparison of patients with mSASSS change $\geq 2 \mathrm{vs}<2$. ** P value for comparison of patients with $\geq 1$ vs 0 new syndesmophytes. VEGF: vascular endothelial growth factor; mSASSS: modified Stoke Ankylosing Spondylitis Spinal Score.

and logistic regression showed no significant association between VEGF levels/changes with subsequent structural changes/spinal inflammation measured by mSASSS/ASspiMRI-a scores, respectively. The lack of corroboration with findings of Poddubnyy, et al ${ }^{13}$, suggesting that VEGF is predictive of radiographic progression, is most likely explained by the major difference in treatment. In the GO-RAISE trial, all patients with AS had been treated with GOL, known to strongly suppress VEGF levels ${ }^{19}$, whereas about $3 \%$ of the German Spondyloarthritis Inception Cohort (GESPIC) patients, a large proportion of whom had axial spondyloarthritis, had been exposed to TNF antagonists ${ }^{13}$.

Our findings are consistent with current knowledge on AS pathogenesis, i.e., inflammation and new bone formation appear to be partially uncoupled (Figure 1). While angiogenesis is involved in early/active disease, once inflammation is largely quelled by TNF antagonism, angiogenesis is also stopped and VEGF levels drop. However, bone formation through syndesmophytes, although initially stimulated by inflammation, continues for several years, as was also

Personal non-commercial use only. The Journal of Rheumatology Copyright (C) 2016. All rights reserved. 
Table 2. Spearman correlation analysis of serum VEGF levels $(\mathrm{pg} / \mathrm{ml})$ and the ASspiMRI-a scores.

\begin{tabular}{lcccc}
\hline ASspiMRI-a Timepoint & Biomarker/timepoint & Patients, $\mathrm{n}$ & $\mathrm{r}_{\mathrm{s}}$ & $\mathrm{p}^{*}$ \\
\hline Baseline score & VEGF at baseline & 67 & 0.14 & 1.000 \\
Week 14 & & & \\
Score & VEGF at baseline & 69 & 0.14 & 1.000 \\
& VEGF at Week 14 & 69 & 0.21 & 1.000 \\
& VEGF change at Week 14 & 67 & 0.13 & 1.000 \\
Change from baseline & VEGF at baseline & 63 & -0.11 & 1.000 \\
& VEGF at Week 14 & 63 & 0.11 & 1.000 \\
& VEGF change at Week 14 & $\mathbf{6 3}$ & $\mathbf{0 . 5 0}$ & $\mathbf{0 . 0 0 1}$ \\
Week 104 & & & \\
Score & VEGF at baseline & 53 & 0.33 & 0.255 \\
& VEGF at Week 14 & 53 & 0.28 & 0.713 \\
& VEGF change at Week 14 & 52 & -0.21 & 1.000 \\
& VEGF at Week 104 & 40 & 0.24 & 1.000 \\
& VEGF change at Week 104 & 33 & -0.33 & 1.000 \\
Change from baseline & VEGF at baseline & 49 & -0.04 & 1.000 \\
& VEGF at Week 14 & 49 & 0.07 & 1.000 \\
& VEGF change at Week 14 & 49 & 0.22 & 1.000 \\
& VEGF at Week 104 & 37 & 0.02 & 1.000 \\
& VEGF change at Week 104 & 33 & 0.05 & 1.000 \\
\hline
\end{tabular}

* Adjusted for multiplicity of testing through the Bonferroni method. Significant correlations are shown in bold face. VEGF: vascular endothelial growth factor; ASspiMRI-a: Ankylosing Spondylitis spine Magnetic Resonance Imaging activity; $\mathrm{r}_{\mathrm{s}}$ : Spearman correlation coefficients.

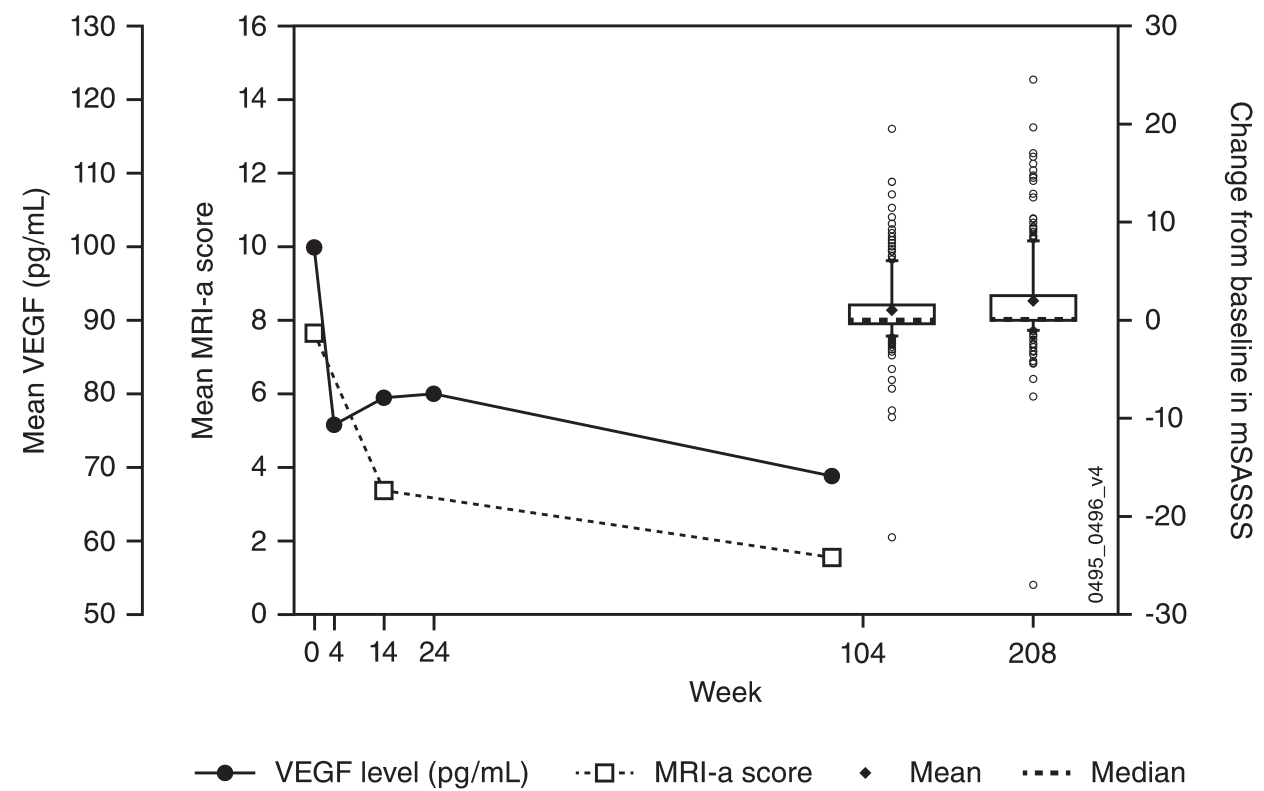

Figure 1. Mean serum VEGF levels, MRI-a scores, and changes in mSASSS over time. VEGF: vascular endothelial growth factor; MRI-a: ankylosing spondylitis spine magnetic resonance imaging-activity; mSASSS: modified Stoke Ankylosing Spondylitis Spinal Score.

observed in the GO-RAISE study ${ }^{8}$. Per the EASIC imaging data, the combination of an inflammatory lesion with a fat MRI signal most commonly yielded new bone formation ${ }^{22}$. Although this particular pathology requires further study, it does not appear to involve increases in VEGF serum levels.

While an advantage of our study may be the homogeneity of an active AS population, our study's smaller sample size and longer disease duration relative to the GESPIC needs to be taken into account when interpreting and comparing the data. Conversely, we analyzed serial VEGF measurements within the same patients, while the GESPIC study did not.

Thus, results presented herein suggest VEGF serum levels 
do not predict new bone formation in patients with AS receiving TNF antagonists.

\section{ACKNOWLEDGMENT}

The authors thank the patients, the investigators, and the study personnel who made this trial possible. The authors also thank Michelle Perate, MS, and Mary Whitman, PhD, of Janssen Scientific Affairs LLC, medical writers who helped draft, collate author comments for, collect approvals for, and submit the manuscript.

\section{REFERENCES}

1. Baraliakos X, Braun J. Biologic therapies for spondyloarthritis: what is new? Curr Rheumatol Rep 2012;14:422-7.

2. Braun J, Baraliakos X, Hermann KG, van der Heijde D, Inman RD, Deodhar AA, et al. Golimumab reduces spinal inflammation in ankylosing spondylitis: MRI results of the randomised, placebo-controlled GO-RAISE study. Ann Rheum Dis 2012; 71:878-84.

3. Robinson PC, Brown MA. The window of opportunity: a relevant concept for axial spondyloarthritis. Arthritis Res Ther 2014;16:109.

4. van der Heijde D, Landewé R, Einstein S, Ory P, Vosse D, Ni L, et al. Radiographic progression of ankylosing spondylitis after up to two years of treatment with etanercept. Arthritis Rheum 2008;58:1324-31.

5. van der Heijde D, Landewé R, Baraliakos X, Houben H, van Tubergen A, Williamson P, et al; Ankylosing Spondylitis Study for the Evaluation of Recombinant Infliximab Therapy Study Group. Radiographic findings following two years of infliximab therapy in patients with ankylosing spondylitis. Arthritis Rheum 2008;58:3063-70.

6. van der Heijde D, Salonen D, Weissman BN, Landewé R, Maksymowych WP, Kupper H, et al; Canadian (M03-606) study group; ATLAS study group. Assessment of radiographic progression in the spines of patients with ankylosing spondylitis treated with adalimumab for up to 2 years. Arthritis Res Ther 2009;11:R127.

7. Baraliakos X, Listing J, Brandt J, Haibel H, Rudwaleit M, Sieper J, et al. Radiographic progression in patients with ankylosing spondylitis after 4 yrs of treatment with the anti-TNF-alpha antibody infliximab. Rheumatology 2007;46:1450-3.

8. Braun J, Baraliakos X, Hermann KG, Deodhar A, van der Heijde D, Inman R, et al. The effect of two golimumab doses on radiographic progression in ankylosing spondylitis: results through 4 years of the GO-RAISE trial. Ann Rheum Dis 2014;73:1107-13.

9. Azizi G, Boghozian R, Mirshafiey A. The potential role of angiogenic factors in rheumatoid arthritis. Int J Rheum Dis 2014; 17:369-83.

10. Meki AR, Al-Shobaili H. Serum vascular endothelial growth factor, transforming growth factor $\beta 1$, and nitric oxide levels in patients with psoriasis vulgaris: their correlation to disease severity. J Clin Lab Anal 2014;28:496-501.
11. Visvanathan S, Wagner C, Marini JC, Baker D, Gathany T, Han J, et al. Inflammatory biomarkers, disease activity and spinal disease measures in patients with ankylosing spondylitis after treatment with infliximab. Ann Rheum Dis 2008;67:511-7.

12. Pedersen SJ, Sørensen IJ, Garnero P, Johansen JS, Madsen OR, Tvede N, et al. ASDAS, BASDAI and different treatment responses and their relation to biomarkers of inflammation, cartilage and bone turnover in patients with axial spondyloarthritis treated with TNF $\alpha$ inhibitors. Ann Rheum Dis 2011;70:1375-81.

13. Poddubnyy D, Conrad K, Haibel H, Syrbe U, Appel H, Braun J, et al. Elevated serum level of the vascular endothelial growth factor predicts radiographic spinal progression in patients with axial spondyloarthritis. Ann Rheum Dis 2014;73:2137-43.

14. Inman RD, Davis JC Jr, Heijde Dv, Diekman L, Sieper J, Kim SI, et al. Efficacy and safety of golimumab in patients with ankylosing spondylitis: results of a randomized, double-blind, placebo-controlled, phase III trial. Arthritis Rheum 2008; 58:3402-12.

15. Braun J, Deodhar A, Inman RD, van der Heijde D, Mack M, Xu S, et al. Golimumab administered subcutaneously every 4 weeks in ankylosing spondylitis: 104-week results of the GO-RAISE study. Ann Rheum Dis 2012;71:661-7.

16. van der Linden S, Valkenburg HA, Cats A. Evaluation of diagnostic criteria for ankylosing spondylitis. A proposal for modification of the New York criteria. Arthritis Rheum 1984;27:361-8.

17. Garrett S, Jenkinson T, Kennedy LG, Whitelock H, Gaisford P, Calin A. A new approach to defining disease status in ankylosing spondylitis: the Bath Ankylosing Spondylitis Disease Activity Index. J Rheumatol 1994;21:2286-91.

18. Deodhar A, Braun J, Inman RD, van der Heijde D, Zhou Y, Xu S, et al. Golimumab administered subcutaneously every 4 weeks in ankylosing spondylitis: 5-year results of the GO-RAISE study. Ann Rheum Dis 2015;74:757-61.

19. Wagner C, Visvanathan S, Braun J, van der Heijde D, Deodhar A, Hsu B, et al. Serum markers associated with clinical improvement in patients with ankylosing spondylitis treated with golimumab. Ann Rheum Dis 2012;71:674-80.

20. Creemers MC, Franssen MJ, van't Hof MA, Gribnau FW, van de Putte LB, van Riel PL. Assessment of outcome in ankylosing spondylitis: an extended radiographic scoring system. Ann Rheum Dis 2005;64:127-9.

21. Braun J, Baraliakos X, Golder W, Brandt J, Rudwaleit M, Listing J, et al. Magnetic resonance imaging examinations of the spine in patients with ankylosing spondylitis, before and after successful therapy with infliximab: evaluation of a new scoring system. Arthritis Rheum 2003;48:1126-36.

22. Baraliakos X, Heldmann F, Callhoff J, Listing J, Appelboom T, Brandt J, et al. Which spinal lesions are associated with new bone formation in patients with ankylosing spondylitis treated with anti-TNF agents? A long-term observational study using MRI and conventional radiography. Ann Rheum Dis 2014;73:1819-25. 
APPENDIX 1. Baseline patient and disease characteristics by subsequent mSASSS change at Week 104 among patients with mSASSS and VEGF data through Week 104. Values are $\%(\mathrm{n} / \mathrm{N})$ or median (mean \pm SD) unless otherwise specified.

\begin{tabular}{|c|c|c|c|}
\hline \multirow[t]{2}{*}{ Baseline Characteristics } & \multicolumn{2}{|c|}{ mSASSS Change at Week 104} & \multirow[t]{2}{*}{$\mathrm{p}^{*}$} \\
\hline & $\geq 2$ & $<2$ & \\
\hline Patients, $\mathrm{n}$ & 23 & 86 & \\
\hline Male & $78.3(18 / 23)$ & $66.3(57 / 86)$ & 0.2706 \\
\hline Age, yrs & $41.0(44.0 \pm 13.98)$ & $40.0(40.6 \pm 11.69)$ & 0.2637 \\
\hline Duration of AS diagnosis, yrs & $9.6(11.9 \pm 10.66)$ & $5.3(9.0 \pm 9.50)$ & 0.1957 \\
\hline HLA-B27-positive & $82.6(19 / 23)$ & $79.1(68 / 86)$ & 0.7072 \\
\hline $\mathrm{CRP}, \mathrm{mg} / \mathrm{dl}$ & $2.2(2.4 \pm 1.84)$ & $1.0(1.5 \pm 1.51)$ & 0.0048 \\
\hline PtGA of disease, $0-10$ & $7.5(7.5 \pm 1.71)$ & $7.2(7.0 \pm 1.71)$ & 0.1885 \\
\hline BASDAI score, 0-10 & $7.0(7.0 \pm 1.50)$ & $6.7(6.8 \pm 1.42)$ & 0.5167 \\
\hline BASFI score, $0-10$ & $6.9(6.8 \pm 1.94)$ & $5.9(5.5 \pm 2.16)^{* *}$ & 0.0067 \\
\hline BASMI score, $0-10$ & $5.0(5.5 \pm 1.78)$ & $3.0(3.3 \pm 2.01)$ & $<0.0001$ \\
\hline mSASSS & $15.3(22.1 \pm 16.39)$ & $2.6(10.7 \pm 18.09)$ & $<0.0001$ \\
\hline
\end{tabular}

* P value for comparison of patients with mSASSS change from baseline to Week $104 \geq 2 \mathrm{vs}<2$. ** $\mathrm{n}=85$. mSASSS: modified Stoke Ankylosing Spondylitis Spinal Score; VEGF: vascular endothelial growth factor; AS: ankylosing spondylitis; CRP: C-reactive protein; PtGA: patient's global assessment; BASDAI: Bath Ankylosing Spondylitis Disease Activity Index; BASFI: Bath Ankylosing Spondylitis Functional Index; BASMI: Bath Ankylosing Spondylitis Metrology Index. 